\title{
The Contribution of Additional Sampling in Cholecystectomy Materials: A Multicenter Prospective Study
}

\author{
Samir ABDULLAZADE ${ }^{1}$, Fahire Göknur AKARCA ${ }^{2}$ (D) Güldal ESENDAĞLI $^{2}$ (D), Nesrin TURHAN ${ }^{3}$ (D),

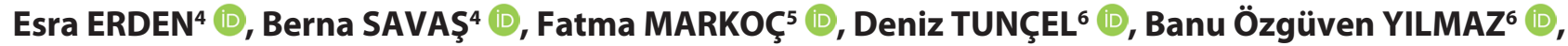

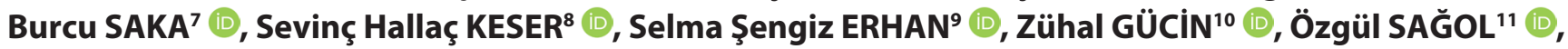 \\ Anıl Aysal AĞALAR ${ }^{11}$ (D), Sevinç ÇELIK ${ }^{12}$ (D), Hatice ÖZER ${ }^{13}$ (D), Ijpek ERBARUT SEVEN ${ }^{14}$ (D), \\ Çiğdem Ataizi ÇELiKEL ${ }^{14}$ (D) Özgür EKINCi² ${ }^{(D)}$, Hatice Reyhan EĞiLMEZ ${ }^{13}$ (D), \\ Serdar BALCI ${ }^{15}$, Gülen AKYOL ${ }^{2}$
}

\begin{abstract}
'Department of Pathology, Izmir Tepecik Education and Research Hospital, IZMIR, TURKEY, ${ }^{2}$ Department of Medical Pathology, Gazi University, Faculty of Medicine, ANKARA, TURKEY, ${ }^{3}$ Department of Pathology, Turkey Yüksek ihtisas Education and Research Hospital, ANKARA, TURKEY,

${ }^{4}$ Department of Medical Pathology, Ankara University, Faculty of Medicine, ANKARA, TURKEY,

Department of Pathology, ${ }^{5}$ Dr. Abdurrahman Yurtaslan Ankara Oncology Education and Research Hospital, ANKARA, TURKEY, ${ }^{6}$ Şişli Etfal Education and Research Hospital, ISTANBUL, TURKEY,

'Department of Medical Pathology, Medipol University, Faculty of Medicine, iSTANBUL, TURKEY,

Department of Pathology, ' ${ }^{2}$ Ütfi Kırdar Education and Research Hospital, ISTANBUL, TURKEY, ${ }^{\circ}$ Okmeydanı Education and Research Hospital, isTANBUL, TURKEY Department of Medical Pathology, ${ }^{10}$ Bezmialem Vakıf University, Faculty of Medicine, iSTANBUL, TURKEY, ${ }^{11}$ Dokuz Eylül University, Faculty of Medicine, iZMIR, TURKEY, ${ }^{12}$ Bozok University, Faculty of Medicine, YOZGAT, TURKEY, ${ }^{13}$ Cumhuriyet University, Faculty of Medicine, SIVAS, TURKEY, ${ }^{14}$ Marmara University, Faculty of Medicine, ISTANBUL, TURKEY, ${ }^{15}$ Pathologist, ANKARA, TURKEY
\end{abstract}

\begin{abstract}
Objective: Cholecystectomy materials are frequently encountered in routine practice. The aim of this study was to determine the true frequency of gallbladder lesions, the diagnostic consistency, and standardization of reports after macroscopic sampling and microscopic evaluation based on previously defined criteria.
\end{abstract}

Material and Method: 14 institutions participated in the study within the Hepato-Pancreato-Biliary Pathology Study Group. Routinely examined cholecystectomies within the last year were included in the study in these institutions. Additional sampling was performed according to the indications and criteria. The number of blocks and samples taken in the first macroscopic examination and the number of blocks and samples taken in the additional sampling were determined and the rate of diagnostic contribution of the additional examination was determined.

Results: A total of 5,244 cholecystectomy materials from 14 institutions were included in the study. Additional sampling was found to be necessary in 576 cases (10.98\%) from all institutions. In the first macroscopic sampling, the mean of the numbers of samples was approximately 4 and the number of blocks was 2 . The mean of the numbers of additional samples and blocks was approximately 8 and 4 , respectively. The diagnosis was changed in 144 of the 576 new sampled cases while the remaining 432 stayed unaltered.

Conclusion: In this study, it was observed that new sampling after the first microscopic examination of cholecystectomy materials contributed to the diagnosis. It was also shown that the necessity of having standard criteria for macroscopic and microscopic examination plays an important role in making the correct diagnosis.

Key Words: Gallbladder, Cholecystectomy, Dysplasia, Cancer, Macroscopy

\section{INTRODUCTION}

Cholecystectomies are frequently encountered in the pathologists' daily routine and are usually performed for various benign etiologies. The common opinion is that all cholecystectomy materials should undergo pathological examination (1). Furthermore, there are a few studies

(Turk Patoloji Derg 2020, 36:188-194)

Received : 06.10.2019 Accepted : 26.02.2020 discussing the pathological examination of the entire cholecystectomy material (2). Gallbladder carcinomas are difficult to detect clinically and radiologically in the early stages and $75 \%$ of malignant cases are not resectable at the time of diagnosis (3). There are various methods for the macroscopic examination of cholecystectomy materials

188 Copyright $\odot 2020$ The Author(s). This is an open-access article published by Federation of Turkish Pathology Societies under the terms of the Creative Commons Attribution License which permits unrestricted use, distribution, and reproduction in any medium or format, provided the original work is properly cited. No use, distribution or reproduction is permitted which does not comply with these terms. 
(4-8) and all these methods are important in detecting incidental gallbladder cancer. The Hepato-PancreatoBiliary (HPB) Pathology Study Group has also conducted a multicenter retrospective study to assess gallbladder lesions and establish common macroscopy and microscopy protocols in our country (9).

There are still some problems in the microscopic approach to the epithelial lesions of the gallbladder. The lesions to be reported, and the indications and criteria for additional sampling are topics of discussion. Although cholecystectomy material is frequently encountered in routine pathology practice, gallbladder epithelial anomalies and neoplasms are uncommon $(10,11)$. Gallbladder epithelial lesions include metaplastic lesions (antral/pyloric metaplasia, intestinal metaplasia), benign epithelial neoplasms (adenomas/adenomyomas), biliary intraepithelial neoplasia (BilIN) (dysplasia/carcinoma in situ), and invasive carcinomas (11). In the differential diagnosis of these lesions, especially the ones that are not macroscopically evident, there are inconsistencies among the observers in approaching these lesions in addition to the problems experienced due to the nature of the lesions.

Protocols that should be followed in the sampling and microscopic evaluation of the gallbladder remain important and controversial since high-grade dysplasia and even invasive carcinomas cannot be diagnosed macroscopically in general (12).

\section{MATERIALS and METHOD}

A total of 23 pathologists from 14 institutions (8 University Hospitals and 6 Training and Research Hospitals) participated in this prospective study within the HPB Pathology Study Group. There is no expert consultation by a single qualified expert for dysplastic lesions. This study included cholecystectomy materials routinely analyzed in these institutions within the last year. We used a form for patient consent. In the first macroscopic examination of the material in accordance with the decided method, the surgical margin of the ductus cysticus was sampled in a way that the sectional side could be seen completely and was sampled completely by removing a full slice from the fundus to the ductus cysticus (Figure 1) (9). All polyps, if present, in the material (including cholesterol polyps) were sampled. Microscopic examinations were continued by examining the new samples in order to find out if any neoplastic polyp with focal epithelial atypia (including denuded epithelium), intestinal metaplasia, or high- or lowgrade dysplasia were detected. In this method, the criteria defined for the reanalysis of macroscopic examination and for additional sampling (AS) were as follows (12):

1) If pyloric-gland metaplasia or mucinous pyloric gland nodules smaller than $3 \mathrm{~mm}$ is detected, there is no need for AS.

2) If a pyloric gland lesion larger than $3 \mathrm{~mm}$ is detected, the material and the container are reevaluated in terms of preinvasive papillary lesions. (No need for AS if the pathology is not observed.)

3) If intestinal metaplasia is detected, 2 cassettes of AS are taken as 2 to 3 samples per cassette.

4) If focal epithelial atypia is detected, 2 cassettes of AS are taken in the same way.

5) If severe atypia is found in addition to the denuded epithelium, 4 cassettes are taken in a similar way.

6) If high-grade dysplasia is detected, at least 12 cassettes are taken in the same way.

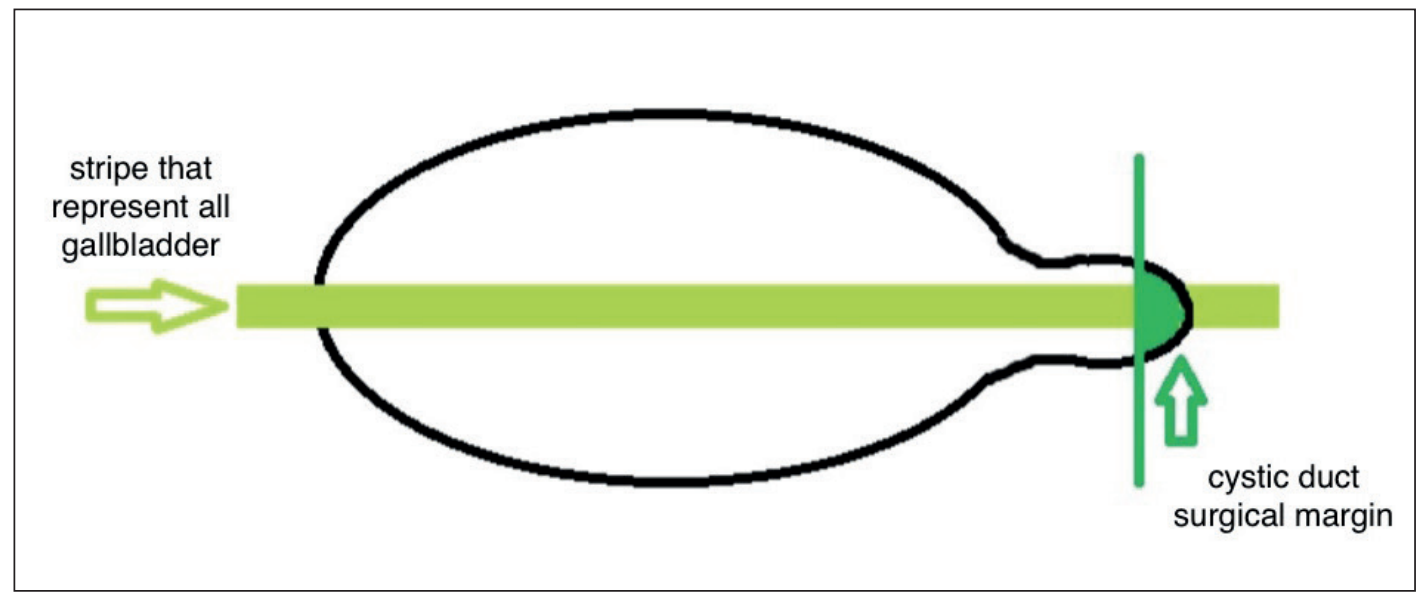

Figure 1: Macroscopic sampling method in gallbladder material. 
7) If a neoplastic polyp with dysplasia of any size is detected, the lesion is sampled completely and, in addition, five cassettes are obtained from the surrounding mucosa.

8) If invasive carcinoma is detected, 7-12 cassettes are taken to show the depth of the lesion and the relationship with the hepatic bed.

In accordance with these methods, the number of blocks and samples taken in the first macroscopic examination of the materials and after AS, as well as the number of new sampled cholecystectomy materials (cases), were reported. The rate of change in histopathological diagnosis following additional examinations of new sampled cholecystectomy materials was reported.

\section{RESULTS}

A total of 5,244 cholecystectomy materials from 14 institutions were included in the study. AS was found to be necessary in 576 cases (10.98\%) from all institutions. Males made up 189 patients while the remaining 387 were female. The average age was 54.3 years. The number of specimens in the first macroscopic sample ranged from 2 to 28 (mean 4.34) and the number of blocks ranged from 1 to 28 (mean 2.01). Among additional sampled cases, the number of additional samples varied between 2 and 51 (mean 8.04) and the number of additional blocks between 1 and 29 (mean 4). Of the 576 new sampled cases, 432 had no change in the diagnosis, while the diagnosis was changed in 144 cases. Adenocarcinoma was found in 10 cases, highgrade dysplasia in 7 , low-grade dysplasia in 40 , reactive/ regenerative atypia in 4, neoplastic polyp in 3 (biliary adenoma-tubular, tubulopapillary, villous), and intestinal metaplasia in 38 (Figure 2, 3A-D).

\section{DISCUSSION}

Epithelial lesions of gallbladder are common in routine practice since cholecystectomy is a frequently performed surgery $(10,13)$. However, neoplasms and epithelial anomalies of the gallbladder are rare. Since even highgrade dysplasia and invasive carcinomas cannot be macroscopically detected in general (12), it is important to develop an easy-to-use, effective and up-to-date protocol for sampling as well as for microscopic evaluation of the gallbladder.

It has been reported that the clinical course is excellent in high-grade dysplasia cases in which invasive carcinoma was detected after AS and also in the in situ carcinoma/highgrade dysplasia cases in which the invasion was excluded after examining the entire material $(14,15)$. In terms of

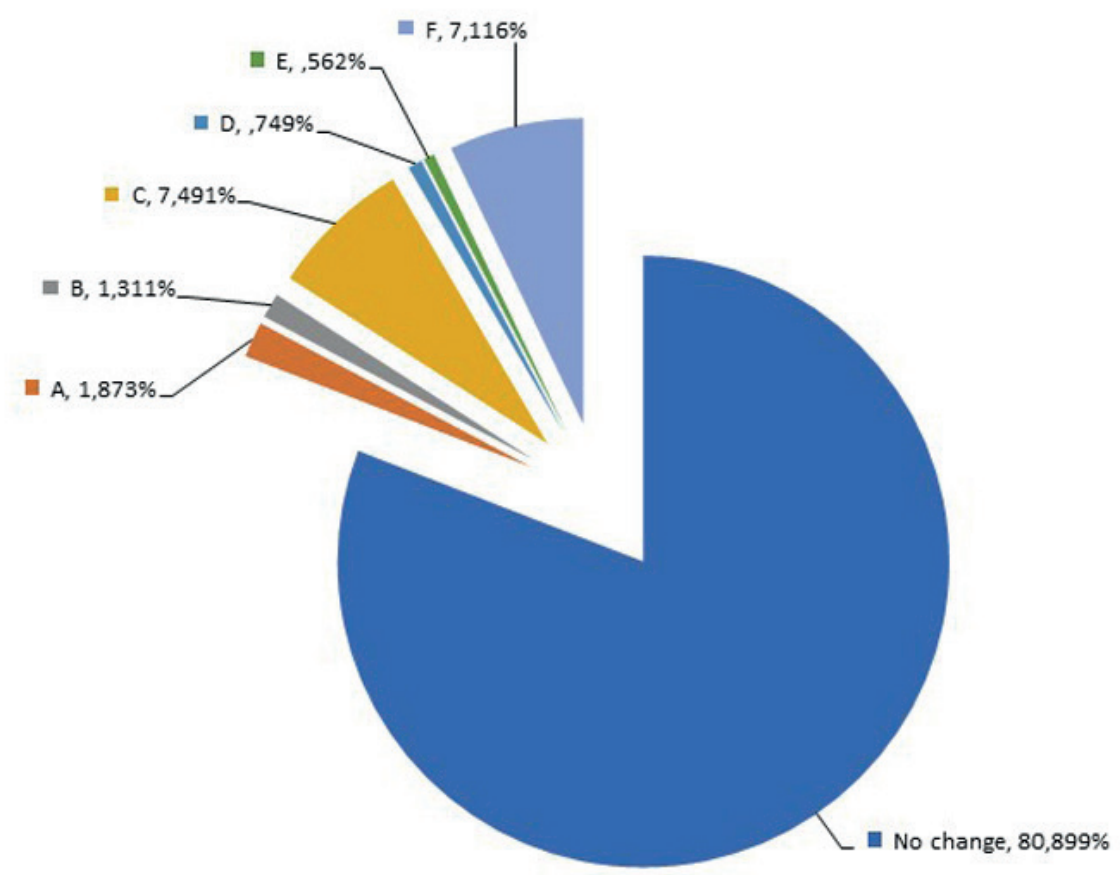

A: Adenocarcinoma. B: High grade dysplasia. C: Low grade dysplasia. D: Reactive/regenerative atypia. E: Neoplastic polyp (biliary adenoma-tubulary/tubulopapillary/villous). F: Intestinal metaplasia.

Figure 2: Frequency of bile duct lesions (all centers). 

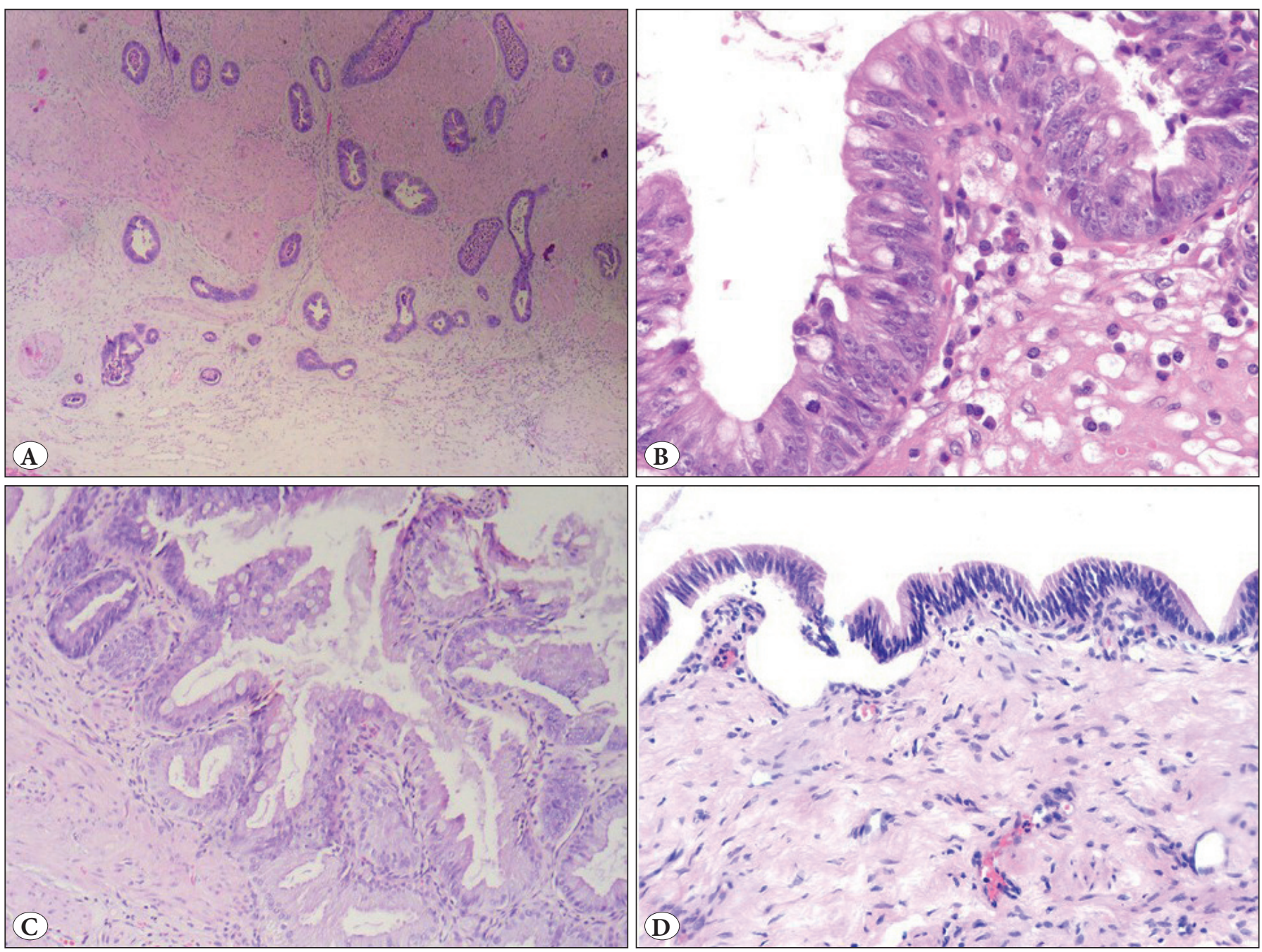

Figure 3: A) Adenocarcinoma (H\&E; x40). B) High grade dysplasia (H\&E; x200). C) Intestinal metaplasia (H\&E; x100). D) Low grade dysplasia (H\&E; x100).

treatment, one of the most important points to keep in mind is that cholecystectomy alone is sufficient in Tis and T1 tumors $(16,17)$, whereas the surgical resection should be extended in cases where deeper invasion is detected $(18,19)$.

Among other pathologies of the gallbladder, pyloric metaplasia is the most common type. Instead of this term, pseudopyloric, antral or mucosal gland hyperplasia is also used. Polyps with pyloric metaplasia, if larger than $1 \mathrm{~cm}$, are categorized as neoplastic (or adenoma) in the presence of dysplasia in the metaplastic area. When chief and parietal cells are seen, heterotopia is the most likely diagnosis instead of metaplasia (10). Intestinal metaplasia, which is characterized by the presence of goblet cells, is less commonly seen than pyloric metaplasia.

It is however known that intestinal metaplasia is related to carcinoma, in a similar way as in the stomach (10).
Examples of other metaplasia types include squamous, neuroendocrine, and pancreatic acinar cell metaplasia (10). AS is strongly suggested in cases where intestinal metaplasia is detected due to the carcinoma relationship described above. Considering the continuity of the gallbladder with bile ducts extending into the liver, the importance of pathology in the cholecystectomy material can be understood. Therefore, identification of all lesions (including hyperplasia and metaplasia) in cholecystectomy material in pathology reports is important both in terms of the database and clinical follow-up of the patients.

In our study, the rate of adenocarcinoma was $1.7 \%$ and this rate is compatible with the literature. The rate of incidental carcinoma in the literature ranges from $0.25 \%$ to $2 \%(20-22)$. In the case of adenocarcinoma found in a cholecystectomy material, the treatment plan also changes. Extension of the surgical resection area, lymphadenectomy, 
or chemo-radiotherapy can be applied to these patients. In this respect, it is important that the parameters required for treatment planning are included in the pathology report. The required parameters can be listed as the type of the procedure, histological type of the tumor, the location and size of the tumor, whether lymph nodes contain metastases or not, and the depth of invasion. In this regard, the macroscopy guide of the HPB Pathology Study Group including gallbladder carcinomas, has been updated and published on the website (23). The latest protocol, also recommended by the College of American Pathologists, emphasizes that the pathology report should include the localization, size, grade, spread, surgical margins of the tumor as well as lympho-vascular and perineural invasion, regional lymph nodes, grade, and additional histopathological findings such as dysplasia/adenoma, cholelithiasis, chronic and acute cholecystitis, intestinal metaplasia, diffuse calcification (porcelain gallbladder), and primary sclerosing cholangitis in the liver bed (24).

There are various methods in the literature for macroscopic examination and sampling of gallbladder resection materials (4-8). The issue of how many new samples should be taken in a case of dysplasia is still controversial $(25,26)$. In addition, the criteria for discrimination between low-grade dysplasia and reactive atypia as well as true diagnosis of such lesions have not been clearly identified (27). Although the rate of dysplasia was reported to be $3.3 \%$ (11), this rate varies in the literature. In another study on this subject, this rate was reported to be $0.4-33.8 \%$ (28). It has also been reported that the gallbladder should be examined completely when dysplasia was observed in the first examination, while there is a study indicating that 4 samples may be sufficient in such cases (25). The authors of this study indicated that the low rate of dysplasia in their series $(<0.5 \%)$ is due to the lower risk for dysplasia of their patient population than other studies or insufficient sampling / low number of samples (i.e. 1 cassette with 2 samples). In a study of Adsay et al. (12), which was conducted in 2013, it was stated that the risk in the population should be taken into account when looking for a neoplastic lesion as the neoplastic lesions cannot always be detected easily, especially during the macroscopic examination. They also emphasized the important knowledge about the presence of various epithelial lesions in association with neoplastic lesions that can be seen in gallbladder. In the recent consensus meeting held in 2015, it was concluded that at least 3 samples should be obtained from routine cholecystectomy materials including the ductus cysticus margin in the geographic regions where the incidence of gallbladder cancer is high, while materials bearing dysplasia or cancer should be fully examined (29).
There are several studies conducted on the frequency of epithelial anomalies and sampling methods in our country $(4,30)$. Argon et al. (4) recommend that a longitudinal sample starting from the neck of the gallbladder to the fundus should be obtained and placed into the cassette as a rolled-up (Swiss roll) figure. Higher rates of pyloric metaplasia, intestinal metaplasia, low-grade dysplasia, and invasive carcinoma were reported with this method compared to the method where the fundus and the body were examined separately. Bolat et al. (30) reported increased rates of metaplasia, dysplasia, epithelial hyperplasia and inflammation by increasing the number of samples obtained from cholecystectomy material. Several methods were suggested in the literature about how macroscopic sampling should be done and the methods to be followed when epithelial atypia is detected $(10,13,31)$.

In our study, the mean number of blocks was 4 in AS cases. In the study of Wrenn et al. (20), which includes the cost analysis, the rate of important pathological lesions detected by histopathological examination of cholecystectomy materials was found to below. Nonetheless, it is necessary to continue to perform histopathological examination in the light of the cost analysis. The authors assert that evaluation of risk factors, intra-operative findings and on-table evaluation of the materials may be an alternative approach (20). In an activity-based cost study conducted in Turkey, the laboratory cost of pathology materials was compared to prices indicated in the Healthcare Regulation Report (32). According to this study, cholecystectomy materials have one of the lowest costs among pathology materials. Given the prevalence and low cost in addition to the importance of early detection of malignancies, it can be assumed that AS is not a significant burden for an institution. However, there is no large-scale study on this topic in our country.

The limitations of our study can be listed as the lack of a standard way for creating the database (i.e. mismatched terminology of the lesions among the institutes or lesions found to be too unimportant to mention in the pathology reports), lack of expert consultation by a single qualified expert for dysplastic lesions; and the lack of demographic, socioeconomic, pre- and postoperative follow-up data and cost-effectiveness analysis of AS during the pathological examination of cholecystectomy specimens.

In conclusion, it was found that obtaining new samples from the gallbladder after the first microscopic examination of material contributed to the diagnosis. In addition, the importance of specifying and using standard criteria for macroscopic and microscopic examination was emphasized in the current macroscopy guide of the HPB Pathology 
Study Group (23). In our study, it was concluded that all pathological findings observed in the cholecystectomy material must be specified in the pathology report.

\section{CONFLICT of INTEREST}

The authors declare no conflict of interest.

\section{REFERENCES}

1. Royal College of Pathologists, Histopathology and cytopathology of limited or no clinical value, in Report of Working Group of the Royal College of Pathologists. 2nd ed. London, 2005.

2. Talreja V, Ali A, Khawaja R, Rani K, Samnani SS, Farid FN. Surgically resected gallbladder: Is histopathology needed for all? Surg Res Pract. 2016; 2016:9319147.

3. Sikora S, Singh R. Surgical strategies in patients with gallbladder cancer: Nihilism to optimism. J Surg Oncol. 2006; 93:670-81.

4. Argon A, Yağcı A, Taşlı F, Kebat T, Deniz S, Erkan N, Kitapçıoğlu G, Vardar E. A different perspective on macroscopic sampling of cholecystectomy specimens. Korean J Pathol. 2013;47:519-25.

5. Albores-Saavedra J, Henson DE, Klimstra DS. Tumors of the gallbladder, extrahepatic bile ducts, and ampulla of Vater. In: Atlas of tumor pathology. Third series, fascicle 27. Washington DC: Armed Forces Institute of Pathology; 2000.

6. Rosai J, Appendix E: Guidelines for handling of most common and important surgical specimens. In: Rosai and Ackerman's Surgical Pathology, Vol:2, 10th ed. Missouri:Elsevier; 2011: 2601.

7. Allen DC, Cameron IA, Loughrey MB. Gallbladder. In: Histopathology Specimens. Clinical, pathological and laboratory aspects. Allen DC, Cameron IA, editors. 2nd ed. Berlin: Springer; 2013. 95.

8. Abraham S. Gallbladder and extrahepatic biliary system. In: Surgical pathology dissection. An Illustrated Guide. Westra WH, Hruban RH, Phelps TH and Isacson C, editors. 2nd ed. Berlin: Springer; 2002. 82-3.

9. Esendağlı G, Akarca FG, Balcı S, Argon A, Erhan Sş, Turhan N, Zengin Nİ, Keser SH, Celik B, Bulut T, Abdullazade S, Erden E, Savaş B, Bostan T, Sağol Ö, Ağalar AA, Kepil N, Karslıoğlu Y, Günal A, Markoç F, Saka B, Özgün G, Özdamar ŞO, Bahadır B, Kaymaz E, Işık E, Ayhan S, Tunçel D, Yllmaz BÖ, Çelik S, Karabacak T, Seven İE, Celikel ÇA, Gücin Z, Ekinci Ö, Akyol G. A retrospective evaluation of the epithelial changes/lesions and neoplasms of the gallbladder in Turkey and a review of the existing sampling methods: A multicentre study. Turk Patoloji Derg. 2018;34:41-8.

10. Adsay NV. Gallbladder, extrahepatic biliary tree, and ampulla. In: Sternberg's diagnostic surgical pathology, Mills SE, editor. Philadelphia: Wolters Kluwer; 2015. 1770.

11. Albores-Saavedra J, Henson DE, Klimstra DS. Benign epithelial tumors of the gallbladder. In: AFIP Atlas of Tumor Pathology. fourth series. Tumors of the gallbladder, extrahepatic bile ducts and vaterian system. Maryland: ARP Silver Spring; 2015. 31, 50.
12. Adsay V, Saka B, Basturk O, Roa JC. Criteria for pathologic sampling of gallbladder specimens. Am J Clin Pathol. 2013;140:278-80.

13. Adsay NV, Klimstra DS. Benign and malignant tumors of the gallbladder and extrahepatic biliary tract. In: Odze and Goldblum Surgical Pathology of the GI Tract, Liver, Biliary Tract, and Pancreas. Odze RD, Goldblum JR, editors. Philadelphia: Saunders; 2015. 1021.

14. Dursun N, Saka B, Balci S, Bagci P, Roa JC, Araja JC, Basturk O, Terry P, Minhas F, Ducato L, Adsay V. Biologic behavior of gallbladder high-grade dysplasia: A long-term survival analysis of 125 cases elucidates a mostly curable disease, which is marker of biliary tract cancer risk in some patients. Mod Pathol. 2014;27: $173 \mathrm{~A}$.

15. Patel K, Balci S, Saka B, Knight J, Basturk O, Sarmiento J, Roa JC, Araya JC, Sweeney J, Terry P, Goodman M, Adsay V. "Carcinoma In-Situ" of the gallbladder: The SEER Database Perspective. Mod Pathol. 2014;27:452A-3A.

16. Lee SE, Jang JY, Lim CS, Kang MJ, Kim SW. Systematic review on the surgical treatment for T1 gallbladder cancer. World J Gastroenterol. 2011;17:174-80.

17. Reid KM, Ramos-De la Medina A, Donohue JH. Diagnosis and surgical manegement of gallbladder cancer: A review. J Gastrointest Surg. 2007;11:671-81.

18. Fong Y, Heffernan N, Blumgart LH. Gallbladder carcinoma discovered during laparoscopic cholesystectomy: Aggressive reresection is beneficial. Cancer. 1998:83:423-7.

19. Foster JM, Hoshi H, Gibbs JF, Iyer R, Javle M, Chu Q, Kuvshinoff B. Gallbladder cancer: Defining the indications for primary radical resection and radical re-resection. Ann Surg Oncol. 2007; 14:833-40

20. Wrenn SM, Callas PW, Abu-Jaish W. Histopathological examination of specimen following cholecystectomy: Are we accepting resect and discard? Surg Endosc. 2017;31:586-93.

21. Lam CM, Yuen AW, Wai AC, Leunmg RM, Lee AY, Ng KK, Fan CT. Gallbladder cancer presenting with acute cholecystitis: A population-based study. Surg Endosc. 2005;19:697-701.

22. Sun CD, Zhang BY, Wu LQ, Lee WJ. Laparoscopic cholecystectomy for treatment of unexpected early-stage gallbladder cancer. J Surg Oncol. 2005;91:253-7.

23. Patoloji Dernekleri Federasyonu Hepato-Pankreato-Biliyer Patoloji Çalışma Grubu Makroskopi Kılavuzu 2017 Güncellemesi. 2017. 1-5. http://www.turkpath.org.tr/upload/content/files/ Hepatopankreatikobiliyer_Calisma_Grubu_Makroskopi_ Kilavuzu_2017.pdf

24. College of American Pathologists. Protocol for the examination of specimens from patients with carcinoma of the gallbladder. Version 4.1.0.0; Februar 2020. https://documents.cap.org/ protocols/cp-gihepatobiliary-gallbladder-20-4100.pdf

25. Renshaw AA, Gould EW. Submitting the entire gallbladder in cases of dysplasia is not justified. Am J Clin Pathol. 2012; 138:3746. 
26. Akki AS, Zhang W, Tanaka KE, Chung SM, Liu Q, Panarelli NC. Systemic selective sampling of cholecystectomy specimens is adequate to detecet incidental gallbladder adenocarcinoma. Am J Surg Pathol. 2019;43:1668-73.

27. Adsay V, Roa JC, Basturk O, Torres J, Mucientes F, Del Pozo M, Villaseca MA, Aguayo G, Bellolio ER, Araya JC, Endo I, Lee K, Jang KT, Jang JY, Ohike N, Shimizu M, Hirabayashi K, Terris B, Zamboni G, Reid M, Xue Y, Bedolla G, Quigley B, Krasinskas A, Akkas G, Memis B, Klimstra D, Hruban RH, Zhu B, Van Dyke $\mathrm{AL}$, Koshiol J. Epithelial atypia in the gallbladder: Diagnosis and classification in an international consensus study. Mod Pathol. 2016;29: 438A-9A.

28. Sasatomi E, Tokunaga O, Miyazaki K. Precancerous conditions of gallbladder carcinoma: Overview of histopathologic characteristics and molecular genetic findings. J Hepatobiliary Pancreat Surg. 2000;7:556-67.
29. Aloia TA, Járufe N, Javle M, Maithel SK, Roa JC, Adsay V, Coimbra FJ, Jarnagin WR. Gallbladder cancer: Expert consensus statement. HPB (Oxford). 2015;17:681-90.

30. Bolat F, Kayaselcuk F, Nursal TZ, Bal N, Tuncer I. The correlation of the histopathological findings by increasing the sample size in cholecystectomies. Turk Patoloji Derg. 2007;23:137-42.

31. Hartman D, Krasinskas AM, Sasatomi E. Caveat emptor: Submitting the entire gallbladder in cases of dysplasia is not justified. Am J Clin Pathol. 2013;139:830.

32. Ergün FA, Ağırbaş İ, Kuzu I. Activity-based costing for pathology examinations and comparison with the current pricing systems in Turkey. Turk Patoloji Derg. 2013:29:1-14. 